\title{
Commentary: Paying a price for plasticity—what the endometrium has to do with it!
}

\author{
David F. Albertini ${ }^{1}$ \\ Published online: 18 May 2019 \\ (C) Springer Science+Business Media, LLC, part of Springer Nature 2019
}

While our embryocentric tendencies currently seem to dominate media outlets of the professional and layperson ilks, it has been clear from the very beginning exactly what the endometrium has to do with all things reproductive. Take for example the classic paper from Noyes, Hertig, and Rock demonstrating how histological dating could identify cycle-related changes underlying the remarkable ability of the endometrium to restore itself following menses [1]. In today's terms, this would be likened to an extreme example of tissue plasticity, meeting all of the criteria endowed upon those rare adult tissues that do indeed exhibit the capacity to regenerate.

In this month's issue of JARG, we focus on the endometrium and what it means to assume its rightful position in the larger scheme of the reproductive axis. As has been known for many years, humans are among the few mammals that exhibit the ability to menstruate - the sine qua non for those species recognizing that a failed reproductive cycle is an immediate ticket to ride into the next opportunity. Opportunists indeed as long as all components of the HPA-pituitary-gonadal axis follow suit!

For starters, we encourage our readers to take in the article from Bellofiore and Evans that posits the evolutionary oddities of a mouse that legitimizes its similarity to humans in being a menstruating species-something $99.9 \%$ of the mice we study as models of human reproduction cannot claim (Monkeys, mice and menses: the bloody anomaly of the spiny mouse; https://doi.org/10.1007/s10815-018-1390). That their subject matter is consonant with our attempt to bring the principles of EVO-DEVO into the realm of human biology has been appreciated previously [2] and forms a platform upon which to address the physiological significance of menstruation in a more mechanistic sense.

David F. Albertini

eicjarg@gmail.com

1 Center for Human Reproduction, New York, NY, USA
Towards this end, we have previously covered topics including the various signaling modalities drawn upon to mediate communication between the conceptus and endometrium, and now consider in depth the immunological dimension of implantation and placentation (see Understanding the role of killer cell immunoglobulin-like receptors in pregnancy complications; https://doi.org/10.1007/s10815-019-01426) and the attendant role subserved by the changing landscape of lymphocyte subpopulations. As the quest for relevant molecular biomarkers for endometrial properties central to normal and pathophysiological states continues unabated, what can be said about the coordinated interactions between cellular constituents-both immune and non-immune types - in patients experiencing abnormalities in reproduction? This is the question Marron and Harrity from the Sims IVF Clinic in Dublin address, using flow cytometry to deliver a much needed portrait of endometrial immune cells in their patient populations (Endometrial lymphocyte concentrations in adverse reproductive outcome populations; doi.org/10. 1007/s10815-019-01427). And we must not overlook the role of genetics and the latest greatest of the -omics approaches if any attempt to provide insight into the regenerative and pathology-prone character of endometrium is to be obtained.

Papers by Vidyahari and colleagues on VEGF genetic polymorphisms (Association of genetic polymorphism of vascular endothelial growth factor in the etiology of recurrent pregnancy loss: a triad study; doi.org/10.1007/s10815-01901431) and one introducing the field of glycomics (Menstrual cycle-dependent alterations in glycosylation: a roadmap for defining biomarkers of favorable and unfavorable mucus; https://doi.org/10.1007/s10815-019-01412) add to our breadth of coverage this month.

In the end, we have all come to know and appreciate the essential role of the endometrium in human reproduction, notwithstanding the fact that how it performs and contributes to our notions of the "windows" of receptivity with regard to implantation is under the strict and immutable direction of 
ovarian steroidogenesis. And to be most specific, the conductor behind this orchestration of plasticity rests firmly in the hands of the folliculo-luteal shift (not to be confused with the luteal-placental shift). To be or not to be a corpus luteum (CL) is the modus operandi that distinguishes the fertile from infertile menstrual cycle. And in these days of fresh versus frozen cycles for embryo transfer, what happens with or without a CL and whatever else may be missing when the CL of pregnancy is carefully eliminated from existence is well worth revisiting in these days of progressive ARTs. If you buy into this line of thinking, you should have a look at the letter from Baker and colleagues for some food for thought (Is a frozen embryo transfer in a programmed cycle really the best option?; doi. org/10.1007/s10815-019-1449).

While making and breaking opportunities for implantation or physiological cycle restart remains under the purview of a $\mathrm{CL}$ and the signals it receives from a hopeful conceptus, on a different scale comes the opportunity to ask just how well contemporary ARTs are doing in terms of serving our patients. Our collective reliance on $P$ values, as some may be aware, has recently come under the close scrutiny of experts in many biomedical research disciplines. And many of the core questions at center stage in human ARTs have yet to move to a satisfactory level of "certainty" to warrant adoption not simply because of the intractability of much of our experimentation, and the inherent design problems and genetic, technical, and practitioner-based heterogeneities, given a history that may be repeating itself, at least in the USA [3]. Somehow in our desire to define success in human ARTs along what has been painted as a progressive deployment of technology and conceptualization, the basic biological facts regarding what is natural for our species [4] and what is realistic to expect with evolving (not necessarily improving) ARTs [5] should bring pause to our ability to self-assess and engage in a form of conflict resolution gratifying to patients and practitioners alike on a global scale given current trends [6].

\section{References}

1. Noyes RW, Hertig AT, Rock J. Dating the endometrial biopsy. Am J Obstet Gynecol. 1975;122(2):262-3.

2. Pavlicev M, Norwitz ER. Human parturition: nothing more than a delayed menstruation. Reprod Sci. 2018;25(2):166-73.

3. Thompson C. IVF global histories, USA: between Rock and a marketplace. Reprod Biomed Soc Online. 2016;2:128-35.

4. Silber SJ, Kato K, Aoyama N, Yabuuchi A, Skaletsky H, Fan Y, et al. Intrinsic fertility of human oocytes. Fertil Steril. 2017;107(5):12327.

5. Patrizio P, Silber S. Improving IVF: is there a limit to our ability to manipulate human biology? J Assist Reprod Genet. 2017;34(1):7-9.

6. Kushnir VA, Barad DH, Albertini DF, Darmon SK, Gleicher N. Systematic review of worldwide trends in assisted reproductive technology 2004-2013. Reprod Biol Endocrinol. 2017;15(1):6.

Publisher's note Springer Nature remains neutral with regard to jurisdictional claims in published maps and institutional affiliations. 